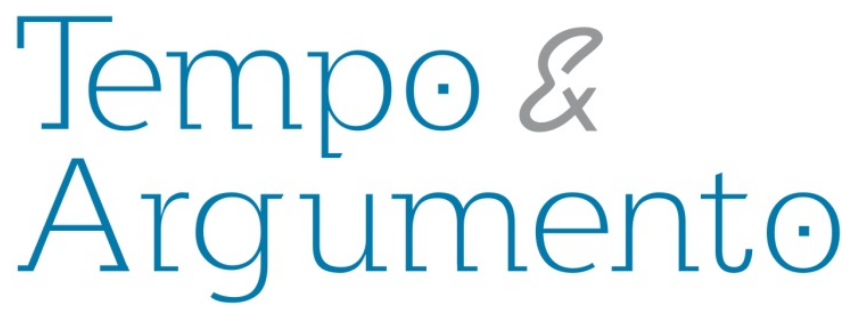

\title{
Memória pública e patrimônio prisional: questões do tempo presente $^{1}$
}

\section{Resumo}

O presente artigo tem como objetivo problematizar processos de patrimonialização ligados à memória pública e ao patrimônio prisional. A elaboração do texto buscou discutir a tensão dentro das escolhas a respeito da preservação e da configuração das prisões como patrimônio cultural, analisando casos que perpassam o século XX e XXI em diferentes espaços, como França, Portugal, Estados Unidos, procurando situar o caso brasileiro dentro dessa tessitura. Abordando o dilema entre o que é escolhido para ser lembrado e a produção do esquecimento, pretende-se refletir sobre a memória pública prisional, dialogando com questões ligadas ao estudo da história do tempo presente e da história pública.

Palavras-chave: Prisões. Usos do Passado. História do Tempo Presente. História Pública.

\section{Para citar este artigo:}

BORGES, Viviane Trindade. Memória pública e patrimônio prisional: questões do tempo presente. Tempo e Argumento, Florianópolis, v. 10, n. 23, p. 310 - 332, jan./mar. 2018.

DOI: $10.5965 / 2175180310232018310$

http://dx.doi.org/10.5965/2175180310232018310

\footnotetext{
1 Pesquisa com apoio do Conselho Nacional de Desenvolvimento Científico e Tecnológico CNPq, Edital Universal 443433/2014-3.
} 


\title{
Public memory and prison patrimony: matters of present time
}

\begin{abstract}
This article tries to question the processes of creating legacy related to public memory and prison patrimony. We discuss here the stress involved in choices on preservation and building of prisons while cultural patrimonies, by analyzing cases occurred in the XXth and XXIth Centuries in France, Portugal and United States, and then trying to connect them to Brazilian context. By approaching the dilemma between what is elected to be remembered and the creation of oblivion, we intend to reflect on public prison memory, by dialoguing with questions related to present time and public history.
\end{abstract}

Keywords: Prisons. Uses of Past. Present Time History. Public History.

\section{Patrimônios dissonantes, difíceis, marginais...}

Em 2002, o Brasil acompanhou pela televisão, em cadeia nacional, a demolição da Casa de Detenção de São Paulo, conhecida como Carandiru. O local ficou famoso em 2 de outubro de 1992, quando a Polícia Militar invadiu o lugar para reprimir uma rebelião, provocando a morte de 111 presos. No ano em que o episódio completou 10 anos, a então considerada maior cidade penitenciária do país e uma das maiores do mundo, foi posta abaixo.

Em 2001, um ano antes da demolição, o estado de São Paulo propôs o tombamento do Conjunto de Edifícios da Penitenciária do Estado, composto pela Casa do Administrador (da década de 20) e a vegetação remanescente da mata atlântica, situadas 
edificações da Casa de Detenção, datadas da década de 1950, ou seja, deixou de fora o próprio Carandiru.

Os espaços prisionais, quando entendidos como patrimônio cultural, se distanciam da definição tradicional de "herança cultural", se inserindo na categoria do que podemos chamar de "novos patrimônios" (POULOT, 2006). Também podem ser lidos como patrimônios dissonantes, carregados de embates éticos, oscilando entre tentativas de preservação e a condenação ao esquecimento. O termo "Patrimônio dissonante" tenta delinear as especificidades de um patrimônio marcado por contradições, pensando "suas repercussões, visto que a dissonância refere-se à discordância ou à falta de acordo e consistência quanto ao seu significado" (ASHWORTH, GRAHAM, TUNBRIDGE, 2007, p. 36).

Tais percepções a respeito do patrimônio refletem a multiplicidade de seus usos na atualidade. Tudo pode vir a ser investido de sentidos patrimoniais. O que é próprio de uma noção que chega ao ponto de se tornar uma palavra de época, conforme coloca Hartog (2017, p. 46), gerando tanto consenso que podemos observar seu emprego em sentidos diversos e por vezes conflitantes. O mesmo podemos dizer em relação à noção de memória, remetendo ambas a um grande número de situações, elas mesmas tecidas em temporalidades e lugares diversos (HARTOG, 2017, p. 42).

Conforme Pierre Nora (1993), há locais de memória porque não há mais meios de memória, então por que preservar espaços e memórias cujos sistemas defasados estão ainda vigentes? Se os meios de memória pertencem ao passado, como preservar o passado que ainda nos é presente? Com irregularidades constantemente denunciadas, há muito conhecidas e invariavelmente reproduzidas. Como preservar "patrimônios difíceis, sensíveis e sombrios" (MENEGUELLO, 2014), "patrimônios marginais" (BORGES, 2017),

\footnotetext{
${ }^{2}$ O processo de tombamento estadual (Resolução 15/01 do CONDEPHAAT - Conselho de Defesa do Patrimônio Histórico Arqueológico, Artístico e Turístico de São Paulo), encontra-se em instrução e ainda não foi concluído.
} 
Na história do tempo presente, o patrimônio cultural e as discussões que cercam a memória e sua preservação, têm contribuído para fomentar o debate a respeito de passados que não passam, cujas consequências seguem reverberando no presente, constantemente apreendidas em disputas de memórias marcadas por usos políticos. Examinarei as tensões entre um passado ainda presente e suas formas de transmissão. Tratarei de processos de patrimonialização, uma tessitura que não visa necessariamente preservar para transmitir um legado futuro, mas para tornar "mais habitável o presente e preservá-lo por ele mesmo: primeiro para seu próprio uso" (HARTOG, 2017, p. 47).

As estratégias de patrimonialização possibilitam a atribuição de novos sentidos, usos e significados, atuando diretamente na construção de determinado valor patrimonial (BORGES, 2012). Esses embates são atravessados por diferentes formas de produção do esquecimento, fenômeno que envolve um espectro de estratégias tão complexo quanto o da própria memória (HUYSSEN, 2014, p. 158). Problematizarei os dilemas que cercam os vestígios deixados pela prisão - apagados, preservados, transmitidos, espetacularizados, apreendidos e/ou recriados em espaços culturais, pensando o papel desses lugares como constitutivos da memória pública prisional, dialogando com questões ligadas ao estudo da história do tempo presente e da história pública.

O presente texto foi dividido em quatro tópicos que se interpenetram por meio de exemplos que perpassam o século XX e XXI, e países como França, Portugal, Estados Unidos, procurando situar o caso brasileiro dentro dessa tessitura. Primeiramente, analisarei os apagamentos e as seleções dos vestígios deixados pelas prisões. Em um segundo momento, as configurações e conflitos na construção da memória prisional, problematizando os enfrentamentos travados, seus limites e possibilidades. Por fim, examinarei as implicações relacionadas às visitas aos espaços prisionais e seus passados difíceis. 


\section{Apagamentos e seleções}

O Brasil possui uma das maiores populações carcerárias do mundo. O último Levantamento Nacional de Informações Penitenciárias, o Infopen 3 , foi divulgado em 8 de dezembro de 2017, informando que o Brasil possui 726.712 pessoas privadas de liberdade. O país assume o terceiro lugar entre os países que mais prendem no mundo, sendo o único país cuja população carcerária segue aumentando ${ }^{4}$.

Apesar de um presente aparentemente tolerante e benevolente perante aos vestígios do passado, em que tudo se torna passível de ser investido de sentidos patrimoniais, seguimos assistindo a sistemáticos apagamentos de edificações dissonantes. Por aqui desde a década de 1960, é possível acompanhar a recorrente destruição de prédios de presídios e penitenciarias desativados, espetáculos com cobertura midiática, dinamite, explosões e colunas de fumaça (SANTOS, 2013, p. 223). Além do Carandiru, podem-se citar outros exemplos como o Instituto Penal Cândido Mendes (1940, Rio de Janeiro, parcialmente demolido em 1994), o Complexo Penitenciário Frei Caneca (1850, no Rio de Janeiro, demolido em 2010), o Presídio de Tiradentes (1852, São Paulo, demolido na década de 1970), etc. Certamente nenhum objeto ou vestígio físico é guia autônomo para épocas remotas, mas ajudam a iluminar o passado quando já sabemos que lhe pertencem (LOWENTHAL, 1998, p. 149 e 159). Se as edificações prisionais e os artefatos deixados pelos presos são formas de conhecer o passado prisional, observa-se ao longo dos anos a destruição de parte dessa possibilidade.

Quando permanecem, esses vestígios são apenas marcas silenciadas do passado, algumas vezes preservados em cumprimento de um dever de memória. Os Arcos de Pedra que serviam como portais de entrada dos Presídios de Tiradentes, em São Paulo e Frei Caneca, no Rio de Janeiro, foram poupados das demolições. Prédios descaracterizados por várias reformas, que cumpriram diferentes funções de confinamento; foram casa de correção a depósito de escravos e cárcere político em dois momentos distintos da história do país (BORGES, 2017).

3 Disponível em: <http://www.justica.gov.br/noticias/mj-divulgara-novo-relatorio-do-infopen-nesta-tercafeira/relatorio-depen-versao-web.pdf>. Acessado em: 27/10/2017.

4 Disponível em: <http://justificando.cartacapital.com.br/2017/12/08/infopen-2017-o-processo-penal-deexcecao-em-numeros/>. Acessado em: 14/12/2017. 
Em 2010 quando foi demolido, Frei Caneca era o mais antigo presídio do Brasil, com 172 anos, local conhecido por abrigar presos políticos tanto na época do Estado Novo - entre eles Graciliano Ramos -, quanto durante a ditadura militar. Tiradentes também é lembrado pela passagem de nomes como Monteiro Lobato, preso durante o Estado Novo (1937-1945) e a ex-presidente Dilma Rousseff, presa durante a ditadura militar, na chamada "Torre das donzelas", edificação em estilo colonial localizada dentro do complexo. Em 1985, o Arco de Tiradentes foi tombado pelo Estado de São Paulo. Declarar determinado bem como patrimônio "muda imediatamente o olhar que se porta sobre ele; permite e proíbe certos gestos (HARTOG, 2017, p. 46). Contudo, nesse caso, a única consequência prática dessa atribuição de sentidos patrimoniais parece ter sido a permanência física do portal. Tanto no Rio de Janeiro como em São Paulo, não há nenhuma indicação a respeito da história dessas edificações junto aos locais por elas ocupados. Certamente a maioria daqueles que transitam cotidianamente pela região desconhecem a história desses monumentos de pedra ou que eles representam.

As sistemáticas demolições são legitimadas pelo discurso que aponta uma promessa de futuro (SANTOS, 2013, p. 223), como se destruir esses locais garantisse profundas transformações e melhorias no sistema penal e no desenvolvimento das cidades, assegurando que histórias marcadas por violência não mais se repitam. Talvez mais do que isso, as demolições e apagamentos parecem ser tentativas de exorcizar tragédias. No caso do Carandiru, talvez um dos exemplos mais emblemáticos nesse sentido, a única consequência efetiva do massacre que deixou 111 mortos foi a demolição das edificações. Em 2016, 24 anos depois do ocorrido, o Tribunal de Justiça anulou os julgamentos que condenaram os 74 PMs envolvidos 5 . Nesse mesmo ano foi construído um monumento chamado "Sonho de Liberdade", erguido no terreno onde antes existia o Pavilhão 9, local do massacre. Ao contrário do que pode indicar em um primeiro momento, a escultura não é uma homenagem aos 111 mortos, mas sim um tributo aos 15 anos da morte de Mário Covas, governador que autorizou a demolição com Complexo do Carandiru em 2001. ${ }^{6}$ Libertar São Paulo do local que remetia a uma das maiores tragédias

\footnotetext{
${ }^{5}$ Disponível em:

<http://www1.folha.uol.com.br/colunas/bernardomellofranco/2016/09/1817475-a-nova-vergonha-docarandiru.shtml>. Acessado em: 12/01/2015.

${ }^{6}$ Disponível em: <http://www.ambiente.sp.gov.br/2016/03/07/sao-paulo-ganha-monumento-emhomenagem-a-mario-covas/>. Acessado em 01/12/2017.
} 
A respeito dos apagamentos sistemáticos de edificações prisionais, pensando apenas em exemplos recentes e sem pretender esgotar o tema, citarei dois casos ocorridos em 2017. No início do ano, uma Rebelião na Penitenciária Agrícola de Monte Cristo, em Roraima, deixou 31 mortos, com cenas de decapitações e violência que reverberaram na mídia nacional e internacional. O lugar possuía uma "favela" improvisada motivada pela superlotação do prédio, com barracos montados pelos próprios presos com materiais como lonas e embalagens de marmitex. O local improvisado, até então timidamente divulgado pela mídia, chegou a abrigar 348 detentos. A "favela" foi desativada e demolida logo após o massacre. As edificações da Penitenciária também foram indicadas para demolição após o ocorrido.

No mesmo ano, um menino de cerca de 13 anos foi encontrado dentro da Penitenciária Major Cesar, no Piauí. A criança foi localizada no prédio da antiga Casa do Diretor, uma ala adaptada, visto a superlotação da instituição, com cerca de 24 presos condenados por crimes como estupro. A velha Casa do Diretor transformada em pavilhão é uma edificação da década de 1970, resquício da proposta de Colônia Agrícola que deu origem ao complexo, propondo o trabalho de detentos em atividades agrárias. Até o final de 2017, a única consequência efetiva para o caso, amplamente divulgado pela mídia, foi a tentativa de demolição do local dias após o ocorrido por ordem da Secretaria de Justiça do Estado o Piauí, execução proibida devido ao andamento das investigações ${ }^{7}$. Essas articulações moldam esquecimentos, elegem apagamentos. As Penitenciárias de Major Cesar e Monte Cristo datam da década de 1970, sendo a primeira considerada modelo de ressocialização de detentos na América Latina quando em sua inauguração. A destruição física desses lugares procura conduzir o esquecimento de episódios sombrios e constituem técnicas de apagamento que, supostamente, livrariam o presente de seus fantasmas.

\footnotetext{
${ }^{7}$ Disponível em: <https://cidadeverde.com/noticias/257871/sindicato-denuncia-demolicao-de-casa-ondecrianca-foi-achada-na-major-cesar $>$. Acessado em: 28/11/2017.
} 
Mais uma vez, a memória pública do Carandiru é exemplar ao transitar entre apagamentos, discursos oficiais e reapropriações que trazem constantemente um passado que não passa. É possível acompanhar o esforço do Estado de São Paulo em sua intervenção em nome da memória do Carandiru, seja na atribuição de determinados sentidos, seja na tessitura de apagamentos. O estado subsidiou a criação de duas instituições de memória voltadas ao Carandiru: o Museu Penitenciário Paulista e o Espaço Memória do Carandiru.

O Museu Penitenciário Paulista foi aberto ao público em 2014, e se propõe a tratar da história do sistema penal no Brasil, focando no caso de São Paulo. A respeito do Carandiru, observa-se a escolha da palavra "motim" em detrimento da palavra "massacre", como forma de atenuar as dimensões do episódio que repercutiu nacional e internacionalmente e suas inúmeras formas de transmissão, como relatos de sobreviventes e testemunhas, livros, músicas, documentários, filmes, peças de teatro, exposições, séries de TV, etc. Já o Espaço Memória do Carandiru, criado em 2007, tem como função, conforme o decreto que institui sua criação, “oferecer ao público em geral informações de caráter histórico, social e cultural sobre o Carandiru" (Decreto estadual n. 52.112, de 30/8/2007). O lugar trata do episódio de forma isolada, como um espetáculo descontextualizado do passado, mostrando o Carandiru e sua história como exceções.

A dimensão e a repercussão do evento traumático certamente incitaram o Estado em tentar cumprir seu dever de memória, criando duas instituições oficiais, configurando espaços de evocação do ocorrido no presente, selecionando o que deveria ser lembrado e, principalmente, organizando o esquecimento. Tentativas de controle da memória pública, abusos de memória. Contudo, "tentar legislar sobre o esquecimento [...] é tão inútil quanto tentar legislar sobre as maneiras corretas de lembrar” (HUYSSEN, p. 160).

A memória transcende as tentativas de controle e produz discursos múltiplos. Os aniversários do massacre são sistematicamente acompanhados por atos públicos com a participação de familiares de presos e pessoas que vivenciaram algum tipo de violência de Estado. As discussões públicas, através de grupos e movimentos sociais, ganham uma dimensão ampla, inserindo o Carandiru em debates a respeito das condições de encarceramento, sobre o caráter seletivo do sistema penal e prisional e sobre o uso da 
violência pelo Estado, tornando o Carandiru uma metáfora para novas tragédias prisionais (BORGES, 2016). Essas apropriações do passado são potencializadas pelo acesso público a todo o processo e outros documentos, como fotografias e relatórios, através da Plataforma Memória Massacre Carandiru ${ }^{8}$, criada em 2015, pela Fundação Getúlio Vargas (FGV) e a Associação Nacional de Direitos Humanos, Pesquisa e Pós-Graduação (Andhep).

Cada aniversário é acompanhado de novos usos de um passado que não passa. Em 2 de outubro deste ano, 2017, quando o episódio completou 25 anos, foi amplamente divulgado na mídia o caso de um ex-funcionário que possui um acervo particular de cerca de 5 mil peças referentes ao Carandiru. Sua intenção é "criar um museu em memória àquele que já foi o maior presídio da América Latina" 9 . Rememorar atualiza a tragédia, torna fluidas as fronteiras entre passado e presente, impulsiona a atribuição de novos sentidos.

\section{Vestígios sensíveis}

Um dos caminhos na tessitura do processo de patrimonialização dos espaços prisionais, em seus variados aspectos, está relacionada à história política e à história dos direitos civis e da violência de Estado. Na América Latina, essas questões são trazidas à tona pela delicada revisitação de espaços ligados à ditadura, um movimento que se pode perceber nas últimas duas décadas. Nesse sentido, algumas instituições foram criadas em lugares que funcionavam como centros de aprisionamento e tortura, e se colocam como maneiras encontradas para se relacionar com memórias difíceis (RICOEUR, 2007), rememorando a dor dos processos vividos. Como é o caso do Parque da Paz Vila Grimaldi, no Chile, propriedade transformada em centro de detenção após o golpe; o Museo de la Memoria de Rosario, na Argentina, localizado no prédio que serviu de sede ao Comando do II Corpo do Exército argentino; o Memorial da Resistência do estado de São Paulo, situado no antigo prédio do Departamento Estadual de Ordem Política e Social de São Paulo (Deops/SP).

\footnotetext{
${ }^{8}$ Disponível em: <https://www.massacrecarandiru.org.br>. Acessado em: 23/11/2017.

9 Disponível em: <http://www1.folha.uol.com.br/cotidiano/2017/10/1923468-ex-funcionario-guarda-objetosdo-carandiru-e-sonha-em-criar-museu.shtml>. Acessado em: 20/11/2017.
} 
De forma um pouco diferente vêm sendo tratada a memória pública relacionada aos presos comuns. Conforme Myriam Sepúlveda dos Santos (2013, p. 237), no trabalho de criação do Museu do Cárcere, somente a partir da década de 1980 foi possível encontrar relatos de presos comuns que passaram pelos Presídios da Ilha Grande, no Rio de Janeiro. De acordo com a autora: "Os presos políticos, oriundos em sua maioria de setores da população que detinham mais recursos e poder, conseguiram dar visibilidade ao que vivenciaram e presenciaram". Já os presos comuns eram "majoritariamente jovens, pobres, negros ou mestiços, com pouca ou nenhuma educação, e sem acesso à imprensa, à justiça, ou aos fóruns de participação política”. Portanto, pouco ou nada puderam deixar ou dizer sobre si.

Michael Welch $(2015,2016)$, ao se propor a visitar dez museus de prisão em seis continentes, observa que, em geral, estes lugares oferecem uma narrativa simplista, descrevendo uma evolução dos sistemas penais. Trazem a recriação de ambientes, exibição de uniformes, fotografias e documentos que procuram mostrar a história penitenciária ao longo dos anos. No caso dos Museus Penitenciários brasileiros, do Rio de Janeiro e de são Paulo, e do Museu Penitenciário argentino, por exemplo, chama à atenção o uso de objetos deixados pelos presos comuns, os quais ganham destaque no espaço expositivo. Armas falsas usadas em rebeliões, principalmente armas brancas confeccionadas com materiais variados, bíblias falsas que serviam de esconderijo para armas, cachimbos e utensílios para o consumo de drogas, aparelhos artesanais para realização de tatuagens, engenhocas que serviam para fazer cachaça, cordas usadas para tentativas de fuga, etc.

Os vestígios deixados por presos comuns são apresentados simplesmente como atos criativos ou como prova da engenhosidade e astúcia dos detentos; são exibidos de forma alegórica, como respostas às curiosidades do visitante. Observa-se a ausência de reflexão sobre as condições que levaram esses sujeitos a criarem os objetos em questão. A mediação da memória pela narrativa é marcada pela ausência de discussões a respeito da prisão e suas implicações na atualidade, mantendo os visitantes a uma distancia segura da realidade prisional. Sua exibição alegórica atua como estratégia de apagamento, arranjo de memória que corrobora a ausência de reflexão. Tornam-se meros indícios de uma realidade exterior e distante dos visitantes. 
A busca por retratar o que seria a realidade prisional em suas diferentes perspectivas, parece ser preocupação constante dentro das estratégias de ação que tecem a memória prisional na atualidade. Em 2017, foi inaugurado o chamado The portuguese prison photo Project ${ }^{10}$, um projeto que teve início em Portugal, no Centro Português de Fotografia (CPF), o qual funciona no antigo edifício do Tribunal e Cadeia da Relação do Porto, e que deve seguir em outros países europeus no próximo ano. A intenção é proporcionar uma geral visão das prisões portuguesas na contemporaneidade, inserindo-as em uma história mais ampla. Da maior e mais antiga prisão, que data da década de 1880, à mais recente, que abriu as portas em 2004, há sete estabelecimentos prisionais que representam aproximadamente um quarto de todos os locais de detenção do país. Para isso, fotografias de antigas prisões foram selecionadas por uma historiadora, especialista em história das prisões, Maria José Moutinho Santos, da Universidade do Porto. As imagens, realizadas entre 1876 e 1974, foram escolhidas num universo de muitas centenas pertencentes aos acervos de diversos arquivos públicos portugueses. O fio condutor da exposição são as condições de vida dos presos no decorrer da história, contrapondo imagens "antigas" a imagens "atuais”, registradas por dois fotógrafos em diferentes prisões, procurando retratar espaços, pessoas e vestígios sensíveis.

Em países como a França, a discussão sobre a preservação patrimonial dos espaços prisionais propõe que sejam pensadas as potencialidades da memória pública das prisões em suas distintas formas e possibilidades, preocupações que abarcam os vestígios deixados por aqueles que passaram pelo espaço prisional. Em 2014, a Prison de La Santé, em Paris, foi aberta à visitação durante as Jornadas do Patrimônio francês, evento que anualmente marca a presença do patrimônio no espaço público, evidenciando definitivamente a emergência do tema dentro das discussões ligadas ao patrimônio cultural no país. A categoria "patrimônio carcerário" vem sendo delineada nos últimos anos. O historiador Jean Claude Vimont, falecido em 2015, professor da Université de Rouen, foi pioneiro ao tentar esboçar os parâmetros iniciais para a construção de um conceito ainda controverso e com contornos ainda pouco definidos.

\footnotetext{
${ }^{10}$ Disponível em: <http://www.prisonphotoproject.international/pt/pppp-pt.html>. Acessado em: 20/11/2017.
} 
Vimont (2014) compara as discussões atuais a respeito do patrimônio carcerário e suas especificidades, aos debates que cercaram a legitimação do patrimônio industrial na Europa, iniciados na Inglaterra nos anos 1950, e que ganharam notoriedade na década de 1960, "quando importantes testemunhos da arquitetura industrial foram demolidos". A consolidação dos debates a respeito do patrimônio industrial se alastrou por diferentes países que realizaram ou estão realizando inventários sistemáticos de sua herança do processo de industrialização (KÜHL, 2008, 2014). Vimont vislumbrava um movimento inicial de realização de inventários voltados ao patrimônio carcerário em diferentes regiões da França, inclusive a preocupação em preservar "vestígios frágeis", como os grafites e inscrições deixadas por detentos ao longo dos anos.

A preocupação com os "vestígios frágeis" aparece de forma muito contundente na França. Para Vimont (2010, 2014), para além das edificações, a noção de patrimônio carcerário deve abarcar os "arquivos sensíveis", as formas rudimentares de mensagens, inscrições e qualquer tipo de registro ou intervenção no espaço físico, deixadas pelos presos. Uma discussão preocupada em preservar as diferentes experiências de confinamento, de vítimas da repressão política, às inscrições produzidas por prisioneiros comuns, jovens em conflito com a lei, etc. Marcas desse tipo também podem ser encontradas em publicações Francesas (VIMONT, 2010, 2014), entre elas cabe destacar o livro "Prisons: Patrimoine de France" (MANDRES, 2013). A obra apresenta 2500 fotos de prisões francesas, ressaltando as marcas deixadas pelos presos como desenhos, pinturas e escritas em paredes e edificações.

Estes vestígios não são a respeito de crimes ou criminosos; não atestam a regeneração ou a reeducação. São expressões de e sobre seres humanos que se encontram em um espaço transitório, um não lugar, em situações extremamente adversas. A sistemática demolição de espaços prisionais no Brasil vem conduzindo também o apagamento desses "vestígios frágeis" ou "arquivos sensíveis". Dias antes da implosão do Carandiru, foi realizada uma série de 13 imagens produzidas pelo fotógrafo Pedro Lobo, chamadas Espaços Aprisionados ${ }^{11}$. São fotografias de celas que mostram as

\footnotetext{
${ }^{11}$ http://iphotochannel.com.br/exposicao-de-fotografia/inauguracao-de-espacos-aprisionados-serie-criadanos-ultimos-dias-da-penitenciaria-do-carandiru. Acessado em 03/12/2017.
} 

arrumadas, etc. Vestígios demolidos junto com as edificações.

A prisão é o lugar que muitos só se dão conta de que existe quando algo que escapa às normas acontece, como em momentos de rebeliões e violência exibidas pela mídia, ocasiões em que a ameaça tenta transcender o espaço murado, colocando, supostamente, a sociedade em risco. A prisão é um lugar de passagem também marcado por alguma identidade pessoal, construída em um ambiente nada convencional. Esse “não lugar" passa a fazer parte de determinadas vidas. Se o lugar é o espaço e seus usos, o não lugar seria o espaço desprovido de marcas de uso. Preservar as marcas deixadas no espaço prisional pelos detentos não significa congelar o tempo, significa pensar sobre as mutações permitidas pelo cotidiano e suas práticas. Como "ocorre com qualquer prática cultural que se queira preservar, o que preservamos é sua possibilidade de existir" (ALBUQUERQUE JÚNIOR, 2007, p. 17). Preservar a possibilidade de existir desses vestígios e, portanto, sua capacidade de contrastar, de desconcertar, de mobilizar, problematizando as condições que levaram os sujeitos a criá-los.

\section{Enfrentamentos: limites e possibilidades}

Nos Estados Unidos, questões a respeito do patrimônio prisional e seus usos vêm sendo pensadas especialmente por historiadores públicos, interessados em problematizar a memória prisional e seus usos, bem como preocupados em envolver os principais afetados por essa história, ou seja, os presos e seus familiares ${ }^{12}$. A proposta possui dois caminhos conflitantes. De um lado a tentativa de usar os espaços de memória para criticar e humanizar os sujeitos afetados pelo sistema penal; de outro, iniciativas de espetacularização do espaço prisional que contribuem para o silenciamento, instituindo a ausência de reflexão (SEVCENKO, 2016, p. 823). Em um país que, entre 1970 e 2006, teve

\footnotetext{
${ }^{12}$ A esse respeito, ver: (WELCH, 2015), (BRUGGEMAN, 2012), (SMITH \& BERGMAN, 2010), (MORRISSEY \& SCWARZER, 2011), (WILSON, 2008), (STRANGE \& KEMPA, 2003).
} 
O caso de Eastern State Penitentiary, localizada na Pensilvânia, evidencia bem os dois caminhos contraditórios que guiam as escolhas a respeito do passado prisional e suas formas de apropriação nos Estados Unidos no tempo presente. A instituição abriga um Museu prisional em funcionamento desde 1994. O lugar recebe 200 mil visitantes por ano (ELK, 2016), muitos deles interessados em atrações como Terror Behind the Walls ${ }^{13}$, que consiste em seis atrações assombradas, muito procuradas nos dias de halloween. Em contrapartida, em Eastern State, a patrimonialização da Penitenciária tem possibilitado o “diálogo público" sobre questões como criminalidade e justiça (BRUGGEMAN, 2012). A instalação chamada de "Big Graph", uma escultura de aço de 16 metros de altura composta por três conjuntos de estatísticas, visa estabelecer a reflexão sobre a prisão na atualidade. As informações estatísticas são visíveis dependendo da posição do visitante, expondo dados como o crescimento sem precedentes das taxas de encarceramento desde início do século XX, a ruptura racial da população carcerária estadunidense de 1970 até hoje, a classificação de todas as nações do mundo pela taxa de encarceramento, etc. A escultura pode ser atualizada até o ano de 2020 e sua estrutura é acompanhada pela exposição Prisons in the Age of Mass Incarceration, que procura tratar do impacto das prisões nas vidas dos sujeitos diretamente envolvidos, e a necessidade de discussão a respeito das políticas de justiça criminal (ELK, 2016). Essas ações visam discutir a história do sistema carcerário para e com o público diretamente envolvido e/ou afetado pela prisão, ou seja, os detentos e seus familiares e aqueles que habitam regiões vizinhas às prisões (BRUGGEMAN, 2012, p. 172).

Assim, paralelo às exibições que tornam o espaço prisional palco de espetáculos esvaziados de reflexão e sem conexão com os problemas que perpassam o tempo presente, nos Estados Unidos, a memória pública das prisões tem procurado enfatizar a participação e a "influência das comunidades marginalizadas". Tais projetos são inspirados pela public history e podem incluir consultas públicas, relatos de experiência

\footnotetext{
${ }_{13}^{13}$ Disponível em: <https://www.easternstate.org/halloween/>. Acessado em: 17/08/2017.
} 

classificação de objetos, ou mesmo realização de pesquisas", etc. (SEVCENKO,2017, p. 8).

Tais escolhas trazem alguns dilemas ao ofício de historiador, colocando em perspectiva as "condições objetivas de trabalho do historiador profissional, que envolvem tempo limitado e respeito a padrões de análise e crítica nem sempre facilmente compatibilizáveis com os agentes com que interage" (CORRÊA, 2014). A inquietação frente a essas questões perpassa a critica de historiadores franceses, principalmente historiadores do tempo presente, em relação aos limites da public history estadunidense ${ }^{14}$. Na França, ainda que a preocupação em preservar os vestígios sensíveis deixados pelos detentos esteja presente nas discussões a respeito do chamado patrimônio carcerário, propostas que dialoguem com a história pública, no sentindo de construir uma narrativa histórica com e para os sujeitos diretamente envolvidos, não aparecem no centro das discussões a respeito do tema. A Public History praticada nos Estados Unidos, focada principalmente em uma formação voltada ao mercado de trabalho em espaços de memória, implica enfrentamentos ligados às questões colocadas acima. A crítica principal trazida pelos franceses remete a um modelo de história empresarial ou a projetos comunitários de história coletiva para os quais os historiadores seriam contratados, ou seja, estariam a serviço de determinados grupos, o que os tornaria incapazes de exercer livremente seu métier. Sob esta perspectiva, os historiadores públicos são entendidos como simples "facilitadores", mais do que experts imbuídos de autoridade, "mediadores entre os interesses dos atores que testemunharam". Haveria assim uma oposição entre uma "história científica" e o real world limitada por essas questões de mercado (DUMOLIN, 2017, p. 89).

No Brasil, as tentativas de construir o passado prisional por meio dos sujeitos diretamente envolvidos aparecem de forma ainda isolada, configurando importantes vetores para pensar a memória pública prisional. Myrian Sepúlveda dos Santos (2013), pioneira em tratar de temas relacionados à memória das prisões no país, realizou uma

\footnotetext{
${ }^{14}$ A esse respeito, ver: (DOSSE, 2012), (DUMOULIN, 2017).
} 
pesquisa a partir de entrevistas feitas com funcionários e internos das antigas prisões que foram instaladas na Ilha Grande, no Rio de Janeiro, a fim de criar o Museu do Cárcere, inaugurado em 2009. Através de depoimentos de presos políticos e presos comuns, atravessados por sentimentos e emoções, foi possível estabelecer uma conexão mais sensível entre passado e presente, mostrando que a discussão a respeito das prisões é algo extremamente atual.

Em 2012, o projeto de extensão Arquivos Marginais ${ }^{15}$, do Laboratório de Patrimônio Cultural da UDESC, atuou na realização de uma exposição no Memorial da Penitenciária de Florianópolis, cujas edificações datadas da década de 1930, são protegidas pelo município (BORGES, 2012). Em 2017, o projeto retornou ao espaço prisional com o objetivo de discutir as potencialidades da história das prisões, exibida em espaços de memória, em sensibilizar públicos diversos a respeito das práticas institucionais e seus conflitos. A intenção é envolver detentos nessas discussões, propondo que essa cooperação seja o fio condutor para pensar questões referentes à memória prisional, tais como: o que pensam sobre a preservação patrimonial da prisão onde se encontram confinados? O que pensam sobre o Memorial? O que acreditam que precisa ser mostrado àqueles que visitam o lugar? Nessa proposta, a história pública é entendida como "uma plataforma de observação das várias possibilidades de se elaborar representações históricas e refletir sobre suas condições de apropriação coletiva" (MAUAD, 2016). Tal escolha procura considerar o outro e suas diferenças, construindo diálogos, agenciando trocas e promovendo uma multiplicidade de sentidos.

Os dois exemplos brasileiros procuram inserir os sujeitos diretamente envolvidos com o tema das prisões como participantes das narrativas construídas sobre eles e sobre a prisão. O investimento feito atravessado por questões levantadas pela história pública, por aquilo que ela permite fazer dentro de temas que inquietam a história do tempo presente, principalmente aqueles ligados a duas "palavras de época” que perpassaram o presente texto: patrimônio e memória.

\footnotetext{
15 O Projeto Arquivos Marginais foi criado em 2011 e atua na organização de acervos de instituições de isolamento social, como hospitais psiquiátricos, leprosários e prisões. Em 2012, o projeto realizou a exposição "O tempo abre as portas a quem sabe esperar", no Memorial existente dentro da Penitenciária de Florianópolis (BORGES, 2012).
} 


\section{Passados difíceis}

No Brasil uma experiência recente mostra algumas questões a respeito das possibilidades relacionadas à memória prisional. No final do ano de 2016, o Presídio do Ahú (1903), no estado do Paraná, teve algumas de suas edificações demolidas. O lugar estava sem uso há 10 anos e meses antes do início da demolição, uma emissora local promoveu um "reality show fictício" durante uma visita noturna. Guiados por antigos agentes penitenciários, os visitantes foram apresentados à história da instituição, mas também ouviram histórias assustadoras, acompanhadas por encenações que envolviam gritos, zumbis e fantasmas, que remetem a atrações como Terror Behind the Walls, de Eastern State Penitentiary, mencionada anteriormente. A noite de visitação do Ahú teve intensa procura, excedendo o número de vagas.

Por aqui, experiências como essa, que espetacularizam espaços ligados às prisões, ainda são poucas e merecem um levantamento mais aprofundado. Visitações turísticas desse tipo, comuns nos Estados Unidos, remetem ao conceito de Dark Tourism, popularizado por John Lenon e Malcolm Foley na década de 90. A proposta envolve a visitação organizada a lugares marcados por tragédias e/ou marcados por experiencias de dor e/ou trauma, incluindo nesses roterios as visitas às prisões, envoltos pela curiosidade, muitas vezes acompanhados por espetáculos macabros.

Essas visitas, ao invés de procurarem estabelecer "um olhar crítico ao ocorrido em lugares traumáticos" podem, por vezes, se prender "mais à excitação do risco" (MENEGUELLO, 2014). Contudo, esse tipo de turismo pode oscilar entre o entretenimento e a possibilidade de reflexão sobre a realidade observada. Conforme, Seth Bruggeman (2012), historiador público estadunidense, se a busca pelo Dark Tourism, pensando nas visitas às prisões e aos museus de prisão, pode ser entendida como um indicador, estaríamos equivocados ao pensar que os visitantes não estão interessados em aprender sobre esses passados difíceis. Para o autor, esses espaços e as narrativas empregadas podem tornar a história pública das prisões mais envolvente. Ele salienta a importância da presença de ex-detentos como mediadores, o que ajudaria a provocar a reflexão e a 
empatia do público. Nesse sentido, locais como Old Fort Prison e Robben Island ${ }^{16}$, ambos na África do Sul, onde os ex-detentos retornam para falar de suas experiências relacionadas ao apartheid durante as mediações, apontam novas possibilidades de relacionar-se com questões difíceis.

São visitas motivadas por uma aura de autenticidade, de originalidade. Deseja-se estar no lugar onde o sofrimento ocorreu, como uma tentativa de aproximação da realidade. Em locais como a Penitenciária de Eastern State, os visitantes buscam a sensação de que eles chegam muito perto do que seria a vida em uma penitenciária "real", buscam a "autenticidade" (BRUGGEMAN, 2012). Nesse sentido, o projeto de criação do Museu do Cárcere, inaugurado em 2009 na Ilha Grande, no Rio de Janeiro, previa que :

Sem perder sua funcionalidade, a nova estrutura deveria preservar muros, guaritas, prédios, e, dentro deles, vigas, ferragens e parte dos tijolos originais, elementos capazes de permitir que o visitante tivesse acesso à passagem do tempo. Estávamos todos interessados na preservação de algumas das ruínas existentes, devido ao impacto que causava o seu testemunho sobre a presença de mais de cem anos de cárceres na Ilha. (SANTOS, 2013, p. 226)

Imbuídos por esse desejo, muitos visitantes procuram o Museu Penitenciário Paulista, acreditando que o local ocupa o mesmo espaço fisíco do antigo Carandiru, referindo-se ao lugar como « Museu do Carandiru ». Pesquisando no Museu entre 2016 e 2017, presenciei a monitoria voluntária promovida por alguns ex-detentos, com relatos que escapam da plasticidade da narrativa institucional, expondo aquilo que o discurso oficial procura esquecer (BORGES, 2016). Mas será que os visitantes estão interessados em aprender a respeito desse passado difícil? Pesquisas a respeito da experiência dos visitantes que procuram as prisões e os museus de prisão, tombadas ou não, desativadas ou ainda em uso, ainda são escassas. O Museu Penitenciário realiza um questionário de pesquisa de público com uma série de perguntas objetivas sobre a visita, contando com um espaço para "observações”, propondo que o visitante "comente ou enumere aspetos

\footnotetext{
${ }^{16}$ Robben Island, onde ficou prisioneiro Nelson Mandela, abrigou presos políticos e também presos comuns (e também foi um leprosário), e em 1999 recebeu o título de patrimônio da humanidade.
} 

passado recente vem sendo contado, principalmente sobre as escolhas feitas para narrar o passado relacionado ao Carandiru.

\footnotetext{
"Não é motim é MASSACRE!! Mais de 200 presos foram assassinados pelo Estado de São Paulo. É vergonhoso o museu não tratar deste tema." (Dezembro, 2015)

"Queria saber mais sobre o motim de 1992." (Outubro, 2016)

"Deveria abordar mais o assunto do Carandiru." (Fevereiro, 2016)

"Deveriam colocar a lista dos mortos, [...] imagens das celas, vídeos da implosão, fotos dos pavilhões por dentro." (Junho, 2016) "Não entendo como é possível o acervo do museu não retratar o massacre do Carandiru. Chega a ser revoltante essa omissão." (Dezembro, 2016)
}

A história do tempo presente, em seu constante movimento, reflete as comoções que se desenrolam diante de nós, tornando-se objeto de uma renovação sem fim (BÉDARIDA, 2000). Os comentários mostram que, para além da curiosidade em conhecer o espaço prisional, os objetos deixados pelos presos, bem como entrar nas instalações que reproduzem celas de castigo ou mesmo fazer uma "selfie" em frente a uma imagem imensa do Pavilhão 9, como propõe a instituição em sua tentativa de atender a demanda por autenticidade, alguns visitantes estão interessados em refletir a respeito dos embates que cercam a história do sistema penal, cobrando isso da instituição, problematizando as ausências em seu discurso. Para além da experiência arriscada e instigante do contato com o universo prisional, alguns visitantes buscam elementos para a reflexão. São questões que dialogam com vestígios do passado à luz de preocupações do presente.

O presente artigo buscou incitar a reflexão a respeito de passados latentes, cujas consequências seguem atuando no presente. Os dilemas que cercam os processos de patrimonialização ligados à memória pública das prisões e suas escolhas, mostram os conflitos de uma tessitura marcada por apagamentos e silenciamentos. O que é escolhido para ser lembrado, esquecido ou extinto, de forma apaziguadora ou perturbadora,

\footnotetext{
${ }^{17}$ Museu Penitenciária Paulista. Questionário de Avaliação. O questionário é realizado desde o $2^{\circ}$ semestre de 2015. Não tive acesso ao material referente ao ano de 2017.
} 
configura a tessitura da memória pública. Os embates aqui problematizados mostram que a memória pública das prisões não está restrita à reconstrução de uma história sobre o passado, mas aberta como possibilidade de reflexão a respeito de realidade prisional atual, como forma de melhor habitarmos o presente.

\section{Referências Bibliográficas}

ALBUQUERQUE JÚNIOR, Durval Muniz de. Fragmentos do discurso cultural: por uma análise crítica das categorias e conceitos que embasam o discurso sobre a cultura no Brasil. Disponível em: <http://www.cchla.ufrn.br/ppgh/docentes/durval/artigos/segunda remessa/fragmentos_discurso_cultural.pdf>

ASHWORTH, G.J., GRAHAM, Brian, TUNBRIDGE, J.E. Pluralising Pasts: heritage, identity and place in multicultural societies. London: Pluto Press, 2007.

AUGÉ, Marc. Para que vivemos? 1. ed. francesa. Lisboa, 90 Graus, 2006.

BÉDARIDA, François. Tempo presente e presença da história. In: FERREIRA, Marieta de $M$. AMADO, Janaína (Orgs.). Usos \& abusos da história oral. 3. ed. Rio de Janeiro: FGV Editora, 2000. p.219-229.

BORGES, Viviane. O patrimônio cultural e as prisões: apagamentos e silenciamentos. História: Questões \& Debates, Curitiba, v.65, n.1, p. 285-303, jan./jun. 2017.

BORGES, Viviane Trindade. Carandiru: os usos da memória de um massacre. Revista Tempo e Argumento, Florianópolis, v. 8, n. 19, p. 04- 3. set.,/dez., 2016.

BORGES, Viviane. O tempo abre as portas a quem sabe esperar: usos do passado e embates do presente no percurso da exposição realizada na Penitenciária de Florianópolis (SC). Esboços, Florianópolis, v. 21, p. 236-250, 2014.

BORGES, Viviane. Arthur Bispo do rosário está voltAndo: patrimonialização e memória na invenção de um personagem ilustre. Revista Esboços, Florianópolis, 2011.

BRUGGEMAN, Seth. Reforming the carceral past: eastern state penitentiary and the challenge of twenty-first century prison museums. Radical History Review, n.1 CORRÊA, Ricardo Santhiago. História pública como prática e campo de reflexões: debates, 
trajetórias e experiências no brasil. Texto apresentado como parte do relatório da bolsa PNPD 2013-2014, realizado no PPGH-UFF. INSERIR LOCAL, DATA.

DOSSE, Fraçois. Entrevista. Revista Brasileira de História. São Paulo, v. 32, n. 64, p. 341350, 2012.

DUMOULIN, Olivier. O papel social do historiador. Belo Horizonte: Autêntica Editora, 2017.

ELK, Sara Jane. Eastern State Penitentiary Historic Site, Philadelphia Pennsylvania. Revue Histoire Pénitentiaire: Patrimoine Et Architecture Carcérale, v.11, 2016.

FOUCAULT, Michael. Dos suplícios as celas. In: MOTTA, Manoel Barros da (Org). Ditos e escritos III. Rio de Janeiro: Forense Universitária, 2012.

HARTOG, François. Crer em história. Belo Horizonte: Autêntica, 2017.

HUYSSEN, Andreas. Culturas do passado-presente: modernismos, artes visuais, políticas da memória. Rio de Janeiro: Contraponto, 2014.

KÜHL, Beatriz Mugayar. Preservação do patrimônio arquitetônico da industrialização: problemas teóricos de restauro. Cotia, SP: Ateliê Editorial, 2008.

KÜHL, Beatriz. Algumas questões relativas ao patrimônio industrial e à sua preservação. Disponivel em: <http://portal.iphan.gov.br/uploads/publicacao/algumas_questoes_ relativas_ao_patrimonio.pdf $>$. Acessado em 23/11/2017.

LOGAN, William; Reeves, Keir. Remembering places of pain and shame. In: LOGAN, William e Reeves, Keir (Orgs.).Places of pain and shame: dealing with difficult heritage. London/New York, Routlegde, 2009. p. 1-14.

LOWENTHAL, David. Como conhecemos o passado, São Paulo, Projeto História, v. 17, São Paulo, 1998.

MANDRES, Ethienne. Prisons: Patrimoine de France. Paris: LexisNexis, 2013.

MAUAD, Ana. O passado em imagens: artes visuais e história pública. In: SANTHIAGO, Ricardo et al. História Pública no Brasil. São Paulo: Letra e Voz, 2016.

MENESES, Ulpiano Toledo Bezerra de. Do teatro da memória ao laboratório da História: a exposição museológica e o conhecimento histórico. Anais do Museu Paulista, São Paulo, v.2, p.09-42, jan./dez. 1994. 
MENESES, Ulpiano Toledo Bezerra de. A exposição museológica e o conhecimento histórico. In: FIGUEIREDO, Betânia; VIDAL, Diana G. Museus: dos gabinetes de curiosidades à museologia moderna. Belo Horizonte: Argvmentum; Brasília, DF: CNPq, 2005. p. 15-84.

MENEGUELO, Cristina. Patrimônios sombrios, memórias difíceis. In: FLORES, Maria Bernardete Ramos; PETERLE, Patricia (Orgs.) História e arte: herança, memória e patrimônio. São Paulo: Rafael Copetti Editor, 2014, p. 46-66.

MORRISSEY, Kris; SCHWAZER, Marjorie (Eds). Rethinking Incarceration. Museums and Social Issues, v. 6 Issue 2, spring 2011.

NORA, Pierre. Entre memória e história: a problemática dos lugares. Projeto História, São Paulo, n.10, dez. 1993, p.7-28.

POULOT, Dominique. Uma história do patrimônio no Ocidente. São Paulo: Estação liberdade, 2009.

SANTOS, Myriam Sepúlveda dos. Ruínas e testemunhos: o lembrar através de marcas do passado. Revista de Ciências Sociais, n. 39, p. 221-239, out., 2013.

SEVCENKO, Liz. Prison public memory in the era of mass incarceration. American Quarterly, v.8, n.3, p. $823-834$, Sep., 2016,

SEVCENKO, Liz. Public Histories for Human Rights: Sites of Conscience and the Guantánamo Public Memory Project. In: HAMILTON, Paula; GARDNER, James. The Oxford Handbook of Public History. 2017. Disponível em: <http://hihumanities.org/wpcontent/uploads/2014/01/12-Sevcenko-essay-with-addendum.pdf >.

SMITH, Cynthia Duquette; BERMAN, Teresa, You were on Indian Land: Alcatraz Island as Recalcitrant Memory Space, from Places of Memory: The Rhetoric of Museums and Memorials Alabama: University of Alabama Press, 2010, 160-190.

STRANGE, Carol; KEMPA, Michael. Shades of Dark Tourism: Alcatraz and Robben Island. Annals of Tourism Research, v.30, Issue 2, p.386-405, april, 2003.

VIMONT, Jean Claude. La mémoire des murs, 2014. Disponível em: <https://criminocorpus.org/fr/expositions/art-et-justice/la-memoire-des-murs/>. Acessado em 23/07/2017.

VIMONT. Jean Claude. Les graffiti de la maison d'arrêt du Havre, 2010. Disponível em: <http://criminocorpus.hypotheses.org/55>. Acessado em 23/07/2017. 
WELCH, Michael. Escape to prison: penal tourism and the pull of punishment. Berkeley: University of California Press, 2015.

WILSON, Jacqueline. Prison: public memory and dark tourism. New York: Peter Lang Publishing, 2008. 